\title{
Assessment of Nutritional Status in Children with Cerebral Palsy
}

\author{
Mohana $^{1}$ \\ ${ }^{1}$ Associate professor of Pediatrics, Akash institute of medical sciences and research center, Devanahalli, Bangalore, Karnataka, India.
}

\section{Abstract}

Background: Cerebral palsy refers to a group of disorders that affect movement or posture. The present study was conducted to nutrition status in children with cerebral palsy. Subjects and Methods: The present study was conducted on 120 children age ranged 7-16 years diagnosed with cerebral palsy. Nutritional status assessment was based on the TSF and AFA estimates derived from TSF and mid-upper arm circumference (MUAC) measurements. Children were classified into underweight, <5th normal weight, 5-84.89th and overweight, $>85^{\text {th }}$. Result: There were 70 boys and 50 girls in present study. Common type was spastic in 90, dyskinetic in 20 and ataxic in 10 patients. GMFCS levels was level I in 30, level II in 15, level III in 18, level IV in 9 and level V in 48 patients. The mean TSF and AFA Z-scores were significantly lower in low functioning children than in moderate functioning children $(\mathrm{P}<0.05)$. Underweight and overweight prevalence were $13.1 \%$ and $4.9 \%$ respectively. The underweight prevalence was significantly higher in girls than in boys $(\mathrm{P}<0.05)$, whereas overweight prevalence was significantly higher in boys than in girls $(\mathrm{P}<0.05)$. Both underweight $(\mathrm{P}-0.148)$ and overweight $(\mathrm{P}-0.421)$ prevalence was not significantly different across age groups. Underweight prevalence was significantly higher in the low functioning group ( $\mathrm{P}<0.05)$. Conclusion: Authors found that cerebral palsy children face nutritional challenges. It is more common in underweight as compared to overweight children.

Keywords: Cerebral palsy, Nutrition, Overweight.

Corresponding Author: Dr. Mohana, Associate professor of Pediatrics, Akash institute of medical sciences and research center, Devanahalli, Bangalore, Karnataka, India.

Received: April 2020

Accepted: April 2020

\section{Introduction}

Cerebral palsy refers to a group of disorders that affect movement or posture. It is a permanent, but not unchanging, physical disability caused by an injury to the developing brain, usually before birth. ${ }^{[1]}$ It results from non-progressive lesion of the brain acquired during the rapid brain development stage. There are deficits of mental retardation, visual and hearing impairments, speech and language disorders and oral-motor dysfunction. There is incidence of 1.5-2.5 per 1000 live births. Poor oral motor function results into poor growth and nutritional status. ${ }^{[2]}$

It may be mild and cause only a slight disruption of daily life. It can also be more severe, affecting the whole body. ${ }^{[3]}$ According to the gross motor function classification system (GMFCS), children may be obese (level I \& II function). It has been observed that abnormal nutritional status has serious negative health consequences and subjects a significant load not only on affected children, but also on their families and society. ${ }^{[4]}$ There are three predominant types of cerebral palsy and each is characterized by different movement patterns. Movements can be uncontrolled or unpredictable, muscles can be stiff or tight and in some cases people have shaky movements or tremors. Thus, it is vital to increase healthcare provider's awareness about this disorder. ${ }^{[5]}$ The present study was conducted to nutrition status in children with cerebral palsy.

\section{Subjects and Methods}

The present study was conducted in the department of Pediatrics, Sri Adichunchanagiri institute of medical sciences and research center,B G Nagara Nagamangala (tq) Mandya district over a period of 3 years from June 1994 to May 1997. Ethical committee approval was taken. It comprised of 120 children age ranged 7-16 years diagnosed with cerebral palsy.

Data such as name, age, etc. was recorded. Type of CP, severity of impairment and anthropometric measurements were recorded. Functional motor impairment was assessed by the expanded and revised version of the GMFCS. Nutritional status assessment was based on the TSF and AFA estimates derived from TSF and mid-upper arm circumference (MUAC) measurements. MUAC was measured twice using a non-elastic measuring band and the average value recorded to the nearest $0.1 \mathrm{~cm}$. The TSF and MUAC measurements were taken on the hanging arm and from the midpoint of the acromion and olecranon process of the back arm. Arm muscle area (AMA) and AFA were calculated. Children were classified into underweight, $<5$ th normal weight, 5-84.89th and overweight, >85th. Results thus obtained were subjected to statistical analysis. $\mathrm{P}$ value less than 0.05 was considered significant. 
Results

\begin{tabular}{|c|c|c|}
\hline Characteristics & Number & P value \\
\hline \multicolumn{3}{|l|}{ Gender } \\
\hline Male & 70 & \multirow[t]{2}{*}{0.05} \\
\hline Female & 50 & \\
\hline \multicolumn{3}{|l|}{ Types } \\
\hline Spastic & 90 & \multirow[t]{3}{*}{0.001} \\
\hline Dyskinetic & 20 & \\
\hline Ataxic & 10 & \\
\hline \multicolumn{3}{|l|}{ GMFCS levels } \\
\hline Level I & 30 & \multirow[t]{5}{*}{0.01} \\
\hline Level II & 15 & \\
\hline Level III & 18 & \\
\hline Level IV & 9 & \\
\hline Level V & 48 & \\
\hline
\end{tabular}

[Table 1] shows that there were 70 boys and 50 girls in present study. Common type was spastic in 90, dyskinetic in 20 and ataxic in 10 patients. GMFCS levels was level I in 30 , level II in 15, level III in 18, level IV in 9 and level $\mathrm{V}$ in 48 patients. The difference was significant $(\mathrm{P}<$ $0.05)$.

Table 2: Z-scores for the triceps skinfold thickness and arm fat
area by GMFCS levels
\begin{tabular}{|l|l|l|}
\hline GMFCS levels & TSFZ & AFAZ \\
\hline Level I & -0.3 & -0.4 \\
\hline Level II & -0.4 & -0.3 \\
\hline Level III & -0.5 & -0.2 \\
\hline Level IV & -0.5 & -0.3 \\
\hline Level V & -0.4 & -0.2 \\
\hline Children with moderate functioning & -0.3 & -0.4 \\
\hline Children with low functioning & -0.6 & -0.5 \\
\hline
\end{tabular}

[Table 2] shows that the mean TSF and AFA Z-scores were significantly lower in low functioning children than in moderate functioning children $(\mathrm{P}<0.05)$.

Table 3: Prevalence of underweight and overweight children

\begin{tabular}{|l|l|l|}
\hline Age groups (Years) & Underweight & Overweight \\
\hline $6-9$ & $12.2(8.4-17.2)$ & $7.4(4.2-12.8)$ \\
\hline $10-13$ & $13.4(8.6-19.4)$ & $3.8(1.8-8.2)$ \\
\hline $14-17$ & $16.2(9.2-20.4)$ & $2.6(0.8-1.2)$ \\
\hline Gender & & \\
\hline Boys & $8.2(5.6-14.2)$ & $9.4(6.2-13.8)$ \\
\hline Girls & $18.0(14.6-24.2)$ & $0.5(0.2-0.8)$ \\
\hline Functional level & & \\
\hline Moderate & $6.4(3.4-15.2)$ & $7.4(4.6-12.2)$ \\
\hline Lower & $18.2(15.6-22.6)$ & $3.6(2.4-6.6)$ \\
\hline
\end{tabular}

[Table 3] shows that underweight and overweight prevalence were $13.1 \%$ and $4.9 \%$ respectively. The underweight prevalence was significantly higher in girls than in boys $(\mathrm{P}<0.05)$, whereas overweight prevalence was significantly higher in boys than in girls $(\mathrm{P}<0.05)$. Both underweight $(\mathrm{P}-0.148)$ and overweight $(\mathrm{p}=0.421)$ prevalences were not significantly different across age groups. Underweight prevalence was significantly higher in the low functioning group $(\mathrm{P}<0.05)$.
Discussion

There is rarely one single cause of cerebral palsy. For most babies born with cerebral palsy, the cause remains unknown. ${ }^{[6]}$ For a long time, it was believed that cerebral palsy was due to complications at birth, including asphyxia. ${ }^{[7]}$ Researchers now understand that this contributes to only a very small percentage of cases of cerebral palsy. Now, it is generally accepted that cerebral palsy usually arises from a series of causal pathways, i.e. a combination of events that can lead to an injury in a baby's developing brain. ${ }^{[8]}$ In 13 out of 14 cases of cerebral palsy in India, the brain injury leading to cerebral palsy occurs either in the uterus or before 1 month of age. At present, the cause is not well understood for most of these babies. ${ }^{[9]}$ The present study was conducted to nutrition status in children with cerebral palsy.

In present study, there were 70 boys and 50 girls in present study. Common type was spastic in 90, dyskinetic in 20 and ataxic in 10 patients. GMFCS levels was level I in 30, level II in 15 , level III in 18, level IV in 9 and level $\mathrm{V}$ in 48 patients. Tuzun et al, ${ }^{[10]}$ in their study on 447 children with cerebral palsy found that children had lower TSF and AFA Z-scores compared to reference data from healthy children. The prevalence of underweight and overweight among boys was 8.3 and $9.5 \%$, respectively, whereas it was 19.0 and $0.5 \%$ for girls. Underweight was more prevalent in the low functioning children than in moderate functioning children.

We found that mean TSF and AFA Z-scores were significantly lower in low functioning children than in moderate functioning children $(\mathrm{P}<0.05)$. Underweight and overweight prevalence were $13.1 \%$ and $4.9 \%$ respectively. The underweight prevalence was significantly higher in girls than in boys $(\mathrm{P}<0.05)$, whereas overweight prevalence was significantly higher in boys than in girls $(\mathrm{P}<0.05)$. Both underweight $(\mathrm{P}-0.148)$ and overweight $(\mathrm{p}=0.421)$ prevalence were not significantly different across age groups. Underweight prevalence was significantly higher in the low functioning group $(\mathrm{P}<0.05)$.

Polack et $\mathrm{al}^{[11]}$ reported the effect of these feeding difficulties and nutritional status on quality of life (QoL) for 76 rural guardians. Overall, the carers' quality of life (QoL) was assessed as poor (median summary score was $12.5 / 100$ on the 36-item Pediatric Quality of Life Inventory Family Impact Questionnaire Module). Children with higher levels of CP (Gross Motor Function Classification System levels III and IV) had the most feeding difficulties. Though all the mothers worried about the poor intake and feeding problems of their children, those caring for children with the greatest difficulties reported the poorest QoL.

Khurana et $\mathrm{al}^{[12]}$ reported that in their study group the overweight prevalence was $18.2 \%$. This difference may be explained by many factors, such as study designs and sample characteristics. 


\section{Mahana; Nutritianal Status in Children with Cereleral Palsy}

\section{Conclusion}

In this study it was shown children with cerebral palsy face nutritional challenges. It is more common in underweight as compared to overweight children.

\section{References}

1. Grantham-McGregor S, Cheung YB, Cueto S, et al. Developmental potential in the first 5 years for children in developing countries. Lancet 2007; 369: 60-70.

2. Black RE, Victora CG, Walker SP, et al. Maternal and child undernutrition and overweight in lowincome and middle-income countries. Lancet 2013; 382: 427-51.

3. Bell KL, Boyd RN, Tweedy SM, Weir KA, Stevenson RD, Davies PS. A prospective, longitudinal study of growth, nutrition and sedentary behaviour in young children with cerebral palsy. BMC Public Health 2010;10:179.

4. Gladstone M, Mallewa M, Alusine Jalloh A, et al. Assessment of neurodisability and malnutrition in children in Africa. Semin Pediatr Neurol 2014; 21: 50-7.

5. Samson-Fang L, Fung E, Stallings VA, Conaway M, Worley G,
Rosenbaum P, Calvert R, et al. Relationship of nutritional status to health and societal participation in children with cerebral palsy. J Pediatr 2002;141:637-643.

6. Day SM, Strauss DJ, Vachon PJ, Rosenbloom L, Shavelle RM, Wu YW. Growth patterns in a population of children and adolescents with cerebral palsy. Dev Med Child Neurol 2007;49:167-171.

7. Rogozinski BM, Davids JR, Davis RB, Christopher LM, Anderson JP, Jameson GG, Blackhurst DW. Prevalence of obesity in ambulatory children with cerebral palsy. J Bone Joint Surg Am 2007;89:24212426.

8. Kuperminc MN, Stevenson RD. Growth and nutrition disorders in children with cerebral palsy. Dev Disabil Res Rev 2008;14:137-146.

9. Surveillance of cerebral palsy in Europe (SCPE): a collaboration of cerebral palsy surveys and registers. Dev Med Child Neurol 2000;42: 816-824.

10. Tüzün EH, Güven DK, Eker L, Elbasan B, Bülbül SF. Nutritional status of children with cerebral palsy in Turkey. Disability and rehabilitation. 2013 Mar 1;35(5):413-7.

11. Polack S, Adams M, O’Banion D, et al. Children with cerebral palsy in Ghana: malnutrition, feeding challenges, and caregiver quality of life. Dev Med Child Neurol 2018. 60: 914-21.

12. Khurana SR, Hornyak JE, Green L, Hurvitz EA. The prevalence of overweight children with cerebral palsy. Arch Phys Med Rehabil 2005;86:36-37.

Copyright: (C) the author(s), 2020. It is an open-access article distributed under the terms of the Creative Commons Attribution License (CC BY 4.0), which permits authors to retain ownership of the copyright for their content, and allow anyone to download, reuse, reprint, modify, distribute and/or copy the content as long as the original authors and source are cited.

How to cite this article: Mohana. Assessment of Nutritional Status in Children with Cerebral Palsy. Asian J. Clin. Pediatr. Neonatol.2020;8(1):89-91.

DOI: dx.doi.org/10.47009/ajcpn.2020.8.1.21

Source of Support: Nil, Conflict of Interest: None declared. 